Introduction: Distal resection of the pancreas is a routine procedure in high-volume centres. However, the volume of this procedure can vary. This variation plays a very important role in laparoscopic approach of pancreatic surgery and can be a rea challenge if the anatomical situation is underestimated.

Aim of the study: To present our experience in minimally invasive treatment of the pancreatic tumours and to discuss different approaches to different anatomical situations.

Material and methods: We performed a retrospective analysis of patients, who underwent laparoscopic pancreas resection for pancreatic cancer in our hospital since 2014 to 2016 February. According to extension of operation, patients were divided into two groups: distal pancreatectomy and left hemipancreatectomy for cases that required preparation of the portal vein. Demographic characteristics, and operative and postoperative data were compared between both groups. Results: Out of 16 patients, dista pancreatectomy was performed for 7 (43.8\%) and left hemipancreatectomy for $9(56.2 \%)$ patients. For 1 (14.3\%) laparoscopic distal pancreatectomy and for 2 (22.2\%) laparoscopic left hemipancreatectomy patients surgical conversion to laparotomy was performed. The average operation time was 205 (195-245) min for distal pancreatectomy and 412.5 (280-520) min for left hemipancreatectomy group ( $p=0.001)$, blood loss $125(20-250) \mathrm{ml}$ and 250 (50-1800) $\mathrm{ml}$ accordingly $(p=$ 0.138 ). Totally postoperative fistula occurred in 7 (43.8\%) cases; out of them, $5(71.4 \%)$ patients were from the left hemipancreatectomy group.

Conclusions: Laparoscopic left hemipancreatectomy is more complicated than distal pancreatectomy. Extension and technique selection of distal resection of the pancreas depends on the Yonsei criteria and tumour relation to the portal vein.

Key words: laparoscopy, pancreas cancer, pancreas surgery, distal pancreatectomy.

Contemp Oncol (Pozn) 2017; 21 (2): 174-177 DOI: https://doi.org/10.5114/wo.2017.68627

\section{Laparoscopic distal resection of the pancreas. Can be all resections of body and tail of the pancreas called the same?}

\author{
Audrius Šileikis ${ }^{1}$, Augustas Beiša ${ }^{1}$, Virgilijus Beiša ${ }^{1}$, \\ Mindaugas Kvietkauskas ${ }^{2}$, Marius Kryžauskas ${ }^{1}$, Kęstutis Strupas ${ }^{1}$ \\ ${ }^{1}$ Centre of Abdominal Surgery, Vilnius University, Vilnius, Lithuania \\ ${ }^{2}$ Faculty of Medicine, Vilnius University, Vilnius, Lithuania
}

\section{Introduction}

Pancreatic cancer is one of the most aggressive and lethal malignancies. It is the fourth cause of cancer-related death in the United States [1]. Longterm survival in pancreatic cancer is still very low. So far, there is no other effective treatment apart from the surgery, if the disease has not spread locally. This means that pancreatic cancer resection for resectable cancer should always be attempted [2]. The type of surgical procedure provided for resectable pancreatic cancer depends on the tumour localisation and its accordance with blood vessels. Distal pancreatectomy is indicated in cases of pancreatic body or tail malignancy. Recently, minimally invasive techniques have been applied to procedures at multiple centres internationally $[3,4]$.

The first reported operation on a human pancreas was performed by Wandesleben in 1841 [5]. Minimally invasive surgery in the management of pancreatic diseases began in the early 1990s. Distal pancreatectomy with laparoscopic approach was first described in 1992 by Canadian surgeon Michael Gagner. Nowadays this is the most commonly performed laparoscopic pancreatic procedure in high-volume centres [6].

Several studies have shown laparoscopic distal pancreatectomy advantages: shorter hospital stay, decreased blood loss, reduced morbidity, fewer overall complications, faster recovery, and cost effectiveness (due to the shorter hospital stay) in comparison with open surgery [7, 8].

Multiple factors such as: patient's BMI, history of previous operation, underlying disorders (cardio-pulmonary), and Yonsei criteria (describes: restriction of tumour to the pancreas, intact fascial layer between the distal pancreas and the left adrenal gland and kidney, and tumour localization at least 10-20 mm from the celiac axis) must be considered in the selection of patients for laparoscopic distal pancreatectomy procedure [7, 9, 10].

\section{Aim of the study}

To present our experience in minimally invasive treatment of pancreatic tumours and to discuss different approaches to different anatomical situations.

\section{Material and methods}

We retrospectively reviewed the medical records of patients, who underwent laparoscopic distal pancreatectomy for the treatment of suspected pancreatic tumour in Vilnius University Hospital Santariskiu Klinikos from 2014 to 2016 February.

After primary analysis of our collected data, we have found that the necessity of portal vein preparation during distal pancreatectomy was asso- 
ciated with extension of operation. Therefore, we have divided laparoscopic distal pancreatectomy cases into two procedures: ordinary distal pancreatectomy and left hemipancreatectomy.

Two types of operation were performed. The radical antegrade modular pancreatosplenectomy was described previously by Strasberg et al. [11], and the clockwise technique by Asbun and Stauffer [12]. Intraoperative ultrasonography was performed in all cases to localize the lesion and decide upon the resection line. Laparoscopic staplers were used for pancreas resection. All patients diagnosed with malignant tumours underwent splenectomy. Splenectomy was also performed for patients with large tumours near the splenic hilum, because spleen preservation would have been technically challenging. A closed suction drainage tube was inserted toward the left subphrenic space at the pancreatic stump.

The variables that we analysed were as follows: preoperative characteristics (patients gender, age, body mass index), tumour localisation and size, technique of surgery (radical antegrade modular pancreatosplenectomy or clockwise), with or without splenectomy, conversion rate, operation time, presence of fistula (evaluated by classification presented by Bassi et al. [13]), length of stay after operation and results of histological examination (which showed histological type of tumour, the resection was radical (R0) or not (R1) and number of resected lymph nodes).

The cases with surgical conversion were excluded from further analysis of postoperative data (blood loss, operation time, length of postoperative stay and presence of fistula).

All data were analysed with SPSS version 23.0 (IBM SPSS Inc., Chicago, IL, USA). Shapiro-Wilk test was used to check for normal distribution. Parametric data were analysed by Student's $t$-test and expressed as means and standard deviations. Non-parametric data were analysed with the use of Mann-Whitney $U$ test and reported as medians and ranges. Categorical variables were analysed by Fisher's exact test. $P$ values $<0.05$ were considered as statistically significant.

\section{Results}

From 2014 to February 2016, we performed laparoscopic pancreas resections on 16 patients with suspected pancreatic tumour. Out of them, 7 (43.8\%) were male and 9 (56.3\%) were female. The average patients age was 62.7 \pm 17.2 years, body mass index (BMI) - $30.3 \pm 5.1$ (23.4-39.5) $\mathrm{kg} / \mathrm{m}^{2}$, and tumour size $-31.1 \pm 11.6 \mathrm{~mm}$. Seven (43.8\%) patients underwent laparoscopic distal pancreatectomy, and 9 (56.2\%) underwent left hemipancreatectomy. The routine histological investigation of the surgically removed pancreas specimen has established malignancy in 10 (62.5\%) cases. R0 resection rate was 70\% and the average number of resected lymph nodes was 5.2 (1-14). All patients tolerated the surgery well and were discharged from the hospital after 12.6 (5-30) days. The early follow-up period showed no recurrent disease in all cases.
Detailed comparison of laparoscopic ordinary distal pancreatectomy and left hemipancreatectomy cases is presented in the Table 1.

\section{Discussion}

There are few techniques of laparoscopic distal pancreatectomy procedure: radical antegrade modular pancreatosplenectomy (RAMPS) (Fig. 1) described by Strasberg et al. [11] and a clockwise technique (CW) (Fig. 2) described by Asbun and Stauffer [12]. We performed laparoscopic distal pancreatectomies by both of them. Both techniques are good and their choice depends on tumour localization. For patients diagnosed with pancreatic head tumour, which is close to portal vein, we recommend RAMPS technique, because better visualization of blood vessels can be achieved.

Despite selection of the patients, all laparoscopic surgery is known to have some major disadvantages. Difficult handling of bleeding is one such complication. This complication often demands conversion to open surgery. Björnsson et al. found, that the rate of conversion in laparoscopic distal resection of the pancreas varies between $11 \%$ and $30.8 \%$ [8]. We had 3 (18.8\%) cases of massive bleeding. All of them required conversation to open surgery. In the first case (a patient from the left hemipancreatectomy group, operated using RAMPS technique) pancreatic mobility was limited and preparation of blood vessels was complicated, because of tumour invasion in the fascia layer between the pancreas and the left adrenal gland (one of the Yonsei criteria) and massive haemorrhage from the splenic vein occurred. Laparoscopic management of bleeding was inconvenient, because of high BMI $\left(39.4 \mathrm{~kg} / \mathrm{m}^{2}\right)$. The second patient (from the distal pancreatectomy group, CW) had laparoscopically unmanageable bleeding from the splenic edge. In the third case, patient (from the left hemipancreatectomy group, CW) had BMI of $35.3 \mathrm{~kg} / \mathrm{m}^{2}$ and the tumour was located $15 \mathrm{~mm}$ from celiac axis (one of the Yonsei criteria). Bleeding occurred in the beginning of pancreas mobilization from the superior mesenteric vein. There are some publications that present evidence of a decline in complications and conversion to open surgery with the increase in experience with laparoscopic surgery [14]. Another disadvantage is an inability to perform intraoperative frozen sections [15] and high R1 resection rates. In our study R1 resection was observed in $30 \%$ of malignant cases. However, this can be explained by the use of an endoscopic stapler, which can distort results of resection. The relatively small number of removed lymph nodes and RO resection is associated with the learning curve.

Usually distal pancreatectomy is performed with splenectomy. However, the spleen is important for the immune system and spleen-preserving distal pancreatectomy is preferred and advisable only for benign disease, when lymph node removal is not as crucial $[16,17]$. Two major spleen-preserving procedures are the Warshaw procedure, which conserves the spleen by blood flow from the short gastric vessels, and the Kimura procedure, which preserves the spleen with splenic vessels [18]. In our series, 13 (81.3\%) 
Table 1. Comparison of laparoscopic distal pancreatectomy and left hemipancreatectomy data.

\begin{tabular}{|c|c|c|c|}
\hline Parameter & $\begin{array}{l}\text { Laparoscopic distal } \\
\text { pancreatectomy } \\
(n=7)\end{array}$ & $\begin{array}{l}\text { Laparoscopic left } \\
\text { hemipancreatectomy } \\
(n=9)\end{array}$ & Value of $P$ \\
\hline Female/male $(n)$ & $3(42.9 \%) / 4(57.1 \%)$ & $6(66.7 \%) / 3(33.3 \%)$ & 0.615 \\
\hline Age (years) & $58.4 \pm 15.5$ & $66 \pm 18.7$ & 0.402 \\
\hline BMI $\left(\mathrm{kg} / \mathrm{m}^{2}\right)$ & $30 \pm 3.7$ & $30.5 \pm 6.2$ & 0.855 \\
\hline $\begin{array}{l}\text { Tumor localization }(n) \\
\text { Tail } \\
\text { Body-tail } \\
\text { Body }\end{array}$ & $\begin{array}{c}6(85.7 \%) \\
1(14.3 \%) \\
0\end{array}$ & $\begin{array}{l}2(22.2 \%) \\
4(44.4 \%) \\
3(33.3 \%)\end{array}$ & 0.049 \\
\hline Tumor size (mm) & $32.86 \pm 14.4$ & $29.8 \pm 9.6$ & 0.616 \\
\hline $\begin{array}{l}\text { Operation technique }(n) \\
\text { RAMPS } \\
\text { CW }\end{array}$ & $\begin{array}{c}0 \\
7(100 \%)\end{array}$ & $\begin{array}{l}4(44.4 \%) \\
5(55.6 \%)\end{array}$ & 0.089 \\
\hline Splenectomy (n) & $5(71.4 \%)$ & $8(88.9 \%)$ & 0.55 \\
\hline Intraoperative complication ( $n$ ) & $1(14.3 \%)$ & $2(22.2 \%)$ & 1 \\
\hline Surgical conversion $(n)$ & $1(14.3 \%)$ & $2(22.2 \%)$ & 1 \\
\hline Blood loss $(\mathrm{ml})^{\star}$ & $125(20-250)$ & $250(50-1800)$ & 0.138 \\
\hline Operation time $(\min )^{*}$ & $205(195-245)$ & $412.5(280-520)$ & 0.001 \\
\hline Presence of fistula $(n)^{*}$ & $2(20 \%)$ & $3(42.9 \%)$ & 1 \\
\hline Postoperative stay (days)* & $7.5(7-16)$ & $9.5(5-30)$ & 0.295 \\
\hline Malingnancy (n) & $3(42.9 \%)$ & $7(77.8 \%)$ & 0.302 \\
\hline $\begin{array}{l}\text { Histology }(n) \\
\text { Ductal adenocarcinoma } \\
\text { Neuroendocrine tumor } \\
\text { Mucinous cystadenocarcinoma } \\
\text { Insulinoma } \\
\text { Mucinous cystadenoma } \\
\text { Chronic pancreatitis } \\
\text { Heterotopic splenic tissue }\end{array}$ & $\begin{array}{c}0 \\
2(28.6 \%) \\
1(14.3 \%) \\
1(14.3 \%) \\
1(14.3 \%) \\
1(14.3 \%) \\
1(14.3 \%)\end{array}$ & $\begin{array}{c}5(55.6 \%) \\
1(11.1 \%) \\
0 \\
1(11.1 \%) \\
2(22.2 \%) \\
0 \\
0\end{array}$ & - \\
\hline RO resection $(n)$ & $2(66.7 \%)$ & $5(71.4 \%)$ & 0.569 \\
\hline Resected lymph nodes ( $n$ ) & $4.7(1-9)$ & $5.6(1-14)$ & 0.683 \\
\hline
\end{tabular}

* The cases with surgical conversion were excluded from data analysis

$B M I$ - body mass index; RAMPS - radical antegrade modular pancreatosplenectomy; $C W$ - Clockwise technique

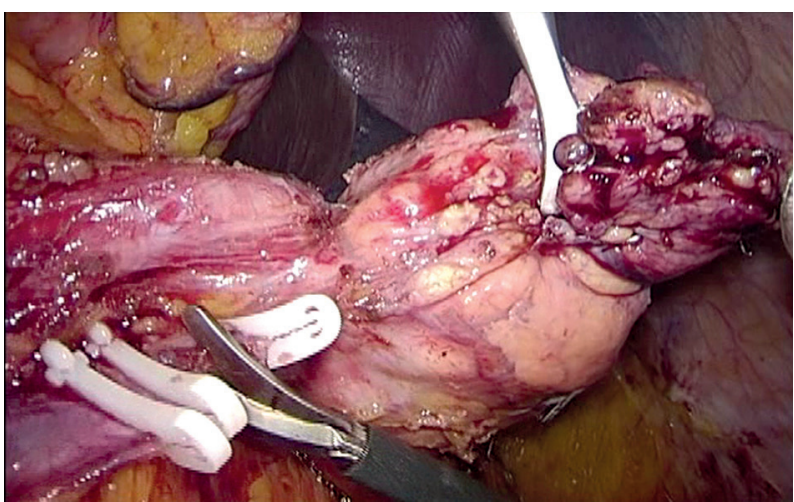

Fig. 1. Radical antegrade modular pancreatosplenectomy

patients underwent splenectomy, most of them because of tumour invasion in the splenic hilum.

In different series, the operating time was reported as longer, similar, or shorter compared with the open approach. This may be explained by the difference in the surgeons learning curve [7]. After the first two laparoscopic

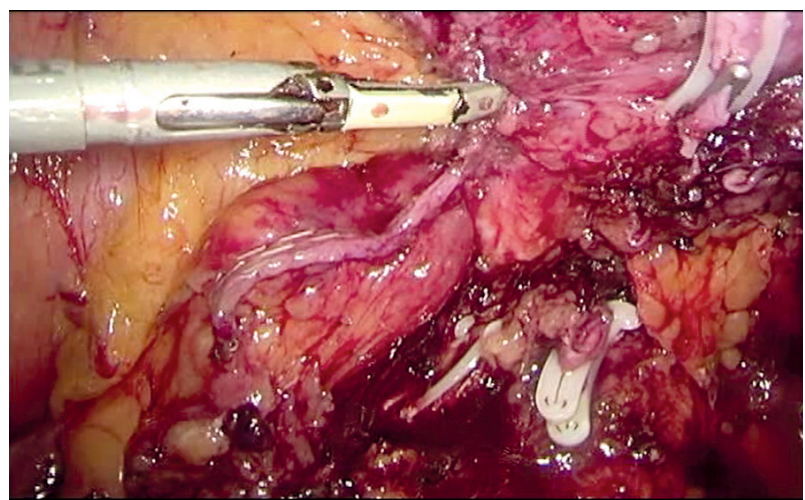

Fig. 2. Clockwise technique of distal pancreatectomy

distal pancreatectomy procedures we almost reduced the average operation time by a factor of almost two.

After primary analysis of our collected data, we found that the necessity of portal vein preparation during distal pancreatectomy was associated with extension of operation. We divided laparoscopic distal pancreatectomy cases 
into two procedures: ordinary distal pancreatectomy and left hemipancreatectomy. In our small case series, there were no notable differences between the distal pancreatectomy and left hemipancreatectomy groups comparing the data of intraoperative complications, surgical conversions, presence of fistula rates, the average blood loss, and postoperative stay, but we found that the left hemipancreatectomy procedure lasted significantly longer.

The most frequent complication after distal pancreatectomy is a postoperative pancreatic fistula, occurring in $4 \%$ to $69 \%$ of patients [19]. In our study, totally postoperative fistula was found in $7(43.8 \%)$ cases. Out of them, $5(71.4 \%)$ patients were from left hemipancreatectomy and 2 (28.6\%) from distal pancreatectomy group. Two (28.6\%) of them were diagnosed with postoperative fistula of type $4 \mathrm{~B}$ and were after surgical conversion, 3 (42.8\%) patients had $4 \mathrm{~A}$ and $2(28.6 \%)-3 \mathrm{~B}$ type fistula. We do not used fibrin glue for fistula prevention, because the results of retrospective reviews and trials are contrary. Several randomized controlled trials have reported effective techniques to prevent postoperative pancreatic fistula (seromuscular jejunal patch, mesh reinforcement, and pasireotide injection), but no strategy has been confirmed in a second consecutive randomised controlled trial [19].

In conclusion, distal resection of the pancreas and left hemipancreatectomy are not identical procedures. Laparoscopic left hemipancreatectomy requires more laparoscopic skills and this procedure should be performed with a growing experience. Extension and technique selection of distal resection of the pancreas depends on the Yonsei criteria and tumour relation to the portal vein.

The authors declare no conflicts of interest.

\section{References}

1. Siegel RL, Miller KD, Jemal A. Cancer Statistics, 2015. CA Cancer J Clin 2015; 65: 5-29.

2. Perysinakis I, Avlonitis S, Georgiadou D, et al. Five-year actual survival after pancreatoduodenectomy for pancreatic head cancer. ANZ J Surg 2015; 85: 183-6.

3. Asbun HJ, Stauffer JA. Laparoscopic vs open pancreaticoduodenectomy: overall outcomes and severity of complications us ing the Accordion Severity Grading System. J Am Coll Surg 2012; 215: 810-9.

4. Mesleh MG, Stauffer JA, Bowers SP, Asbun HJ. Cost analysis of open and laparoscopic pancreaticoduodenectomy: a single institution comparison. Surg Endosc 2013; 27: 4518-23.

5. Schnelldorfer T. The birth of pancreatic surgery: a tribute to Friedrich Wilhelm Wandesleben. World J Surg 2010; 34: 190-3.

6. Subar D, Gobardhan PD, Gayet B. Laparoscopic pancreatic surgery: An overview of the literature and experiences of a single center. Best Pract Res Clin Gastroenterol 2014; 28: 123-32.

7. Damoli I, Butturini G, Ramera M, et al. Minimally invasive pancreatic surgery - a review. Videosurgery Miniinv 2015; 10: 141-9.

8. Björnsson B, Sandström P. Laparoscopic distal pancreatectomy for adenocarcinoma of the pancreas. World J Gastroenterol 2014; 20: 13402-11.

9. Postlewait LM, Kooby DA. Laparoscopic distal pancreatectomy for adenocarcinoma: safe and reasonable? I Gastrointest Oncol 2015; 6: 406-17.

10. Lee SH, Kang CM, Hwang HK, et al. Minimally invasive RAMPS in well-selected left-sided pancreatic cancer within Yonsei criteria: long-term (> median 3 years) oncologic outcomes. Surg Endosc 2014; 28: 2848-55.

11. Strasberg SM, Drebin JA, Linehan D. Radical antegrade modular pancreatosplenectomy. Surgery 2003; 133: 521-7.

12. Asbun HJ, Stauffer JA. Laparoscopic approach to distal and subtotal pancreatectomy: a clockwise technique. Surg Endosc 2011; 25: 2643-9.

13. Bassi C, Butturini G, Molinari E, et al. Pancreatic fistola rate after pancreatic resection: the importance of definitions. Dig Surg 2004; 21: 54-9.

14. Dulucq JL, Wintringer P, Stabilini C, et al. Are major laparoscopic pancreatic resections worthwhile? A prospective study of $32 \mathrm{pa}$ tients in a single institution. Surg Endosc 2005; 19: 1028-34.

15. Küper MA, Eisner F, Königsrainer A, Glatzle J. Laparoscopic surgery for benign and malign diseases of the digestive system: indications, limitations, and evidence. World J Gastroenterol 2014; 20: 4883-91.

16. Iacobone M, Citton M, Nitti D. Laparoscopic distal pancreatectomy: up-to-date and literature review. World I Gastroenterol 2012; 18: 5329-37.

17. Damoli I, Butturini G, Ramera M, et al. Minimally invasive pancreatic surgery. A review. Videosurgery Miniinv 2015; 10: 141-9.

18. Chen JH, Huang KF, Li CH. Preservation of splenic vessels during laparoscopic spleen-preserving distal pancreatectomy via lateral approach. Videosurgery Miniinv 2015; 10: 382-88.

19. Rooij T, Sitarz R, Busch OR, Besselink MG, Abu Hilal M. Technical aspects of laparoscopic distal pancreatectomy for benign and malignant disease: review of the literature. Gastroenterol Res Pract 2015; 2015: 472906.

\section{Address for correspondence}

\section{Audrius Šileikis}

Centre of Abdominal Surgery

Vilnius University

Santariškiu 2

LT-08406 Vilnius, Lithuania

e-mail: audrius.sileikis@santa.lt

Submitted: 3.11 .2016

Accepted: 15.02 .2017 